\title{
Metabolic Changes in a Patient of Methylmalonic Aciduria Treated with D,L-Carnitine Supplement
}

\author{
Naoki Kodo, ${ }^{1,}$ * Naoto Terada, ${ }^{1}$ Zenro KIZaKI, ${ }^{1}$ \\ Toru Yamamoto, ${ }^{1}$ Fumio Inoue, ${ }^{1}$ Nobuaki Furukawa, ${ }^{1}$ \\ Akihiko Kinugasa, ${ }^{1}$ Tadasi Sawada, ${ }^{1}$ and Tomoichi KusunOKI ${ }^{2}$ \\ ${ }^{1}$ Department of Pediatrics, Kyoto Prefectural University of Medicine, \\ Kyoto 602, Japan \\ ${ }^{2}$ Fukui Medical College, \\ Matuoka-cho, Fukui 910-11, Japan
}

(Received September 29, 1986)

\begin{abstract}
Summary Carnitine metabolism in a patient with methylmalonic aciduria was investigated. The patient showed a low level of free carnitine and a slightly increased level of acylcarnitine in her serum and urine. After carnitine therapy, acylcarnitine excretion in the urine increased markedly, and the patient had a favorable body weight gain. A small dose of valine was administered with or without the carnitine supplement. This induced metabolic changes, e.g., hypoglycemia and hyperketonemia, with little changes in lactate, pyruvate and ammonia levels. The level of free carnitine in the serum decreased gradually and acylcarnitine was increased by valine administration. These metabolic changes were not much different with or without carnitine supplement. Natural protein tolerance was then investigated. The patient could not tolerate $1.5 \mathrm{mg} / \mathrm{kg} / \mathrm{day}$ of natural protein because of nausea, vomiting, and body weight loss without carnitine. Although nausea and loss of apetite were also seen under carnitine therapy, vomiting did not occur when the patient received $1.5 \mathrm{mg} / \mathrm{kg} /$ day of natural protein. These results show the usefulness of carnitine for the management of methylmalonic aciduria with restriction of natural protein.
\end{abstract}

Key Words: methylmalonic aciduria, carnitine, valine loading, natural protein tolerance

Recent reports $[1,2]$ show that secondary carnitine deficiency may develop

*To whom correspondence should be addressed. 
in some organic acidurias, particularly in methylmalonic aciduria and propionic acidemia. Several new roles of carnitine have been established recently [3], such as modulation of the intramitochondrial acyl-CoA/CoA ratio [4], utilization of free CoA [5], and detoxication by facilitated removal of excess and potentially toxic acyl groups from the mitochondrion and cell [6].

Carnitine was administered to a patient with methylmalonic aciduria and secondary carnitine deficiency. As a result, a highly increased excretion of carnitine and its metabolites was observed in her urine and a good clinical course was also noted. Therefore we designed a short term admission study for the purpose of investigating the carnitine metabolism in this patient and the effectiveness of carnitine therapy for this disorder. The purpose of the study was fully explained to her parents, and they consented with complete understanding.

\section{SUBJECT AND METHODS}

\section{Clinical description}

The patient was a 3-year-8-month-old girl, the first child of healthy unrelated Japanese parents. Pregnancy and delivery were uneventful. At 7 months of age, she showed vomiting, tachypnea, and hypotonia and progressed into a coma after an upper respiratory tract infection. Marked hypoglycemia $(8 \mathrm{mg} / \mathrm{dl})$ and elevated glutamic-oxaloacetic transaminase (GOT, 1,522 IU), glutamic-pyruvic transaminase (GPT, 792 IU), and creatine phosphokinase (CPK, 5,085 IU) were noted upon admission. Serum ammonia and blood gas were not analyzed. Reye's syndrome was clinically suspected and her condition was gradually improved by glucose infusion. At 9 months of age, she again developed respiratory distress and was comatose after the same prodromes observed in the first episode. On this second admission, marked metabolic acidosis was noted, and gas-chromatography of her urine led to a diagnosis of methylmalonic aciduria. Enzymic study of her leukocytes and lymphocytes disclosed that she had a methylmalonyl-CoA mutase deficiency. Treatment with vitamin $\mathrm{B}_{12}$ failed to improve her condition, and so she was put on a low protein diet $(1.0 \mathrm{~g} / \mathrm{kg} /$ day $)$ with a special milk lacking in valine, isoleucine, threonine, methionine, and glycine. At 29 months of age, she had a third admission due to frequent episodes of vomiting and metabolic acidosis induced by upper respiratory tract infection. During this admission an oral administration of D,L-carnitine chloride $(60 \mathrm{mg} / \mathrm{kg} /$ day $)$ was initiated. In spite of the carnitine administration, the patient was forced to have a fourth admission due to a viral infection. On this admission, she had a high temperature, diarrhea and body weight loss, but ketoacidosis was not so marked as noted previously. The delay in growth and development of the patient worsened at each admission.

\section{Laboratory investigations}

Methods. Amino acids in serum and urine were measured with an automatic amino acid analyzer (Shimadzu LC3A). Urine methylmalonic acid was deter- 
mined by the method of Inoue et al. [7]. Carnitine was measured by an enzymatic method according to McGarry and Foster [8] with the slight modification suggested by Seccombe et al. [9]. Preparation of carnitine was performed by the method of Engel et al. [10]. Serum ketone bodies were measured by the method of Harano et al. [11]. All other routine clinical chemical investigations were done by standard methods.

Valine loading test. A valine loading test was done twice, once with and once without carnitine supplementation. Carnitine administration was stopped 1 week before the admission. A test dose of valine, $50 \mathrm{mg} / \mathrm{kg}$ of body weight, was administered orally together with $0.8 \mathrm{~g} / \mathrm{kg}$ /day of natural protein. This dose of valine was tolerable for this patient in the absence of carnitine therapy; although metabolic changes, e.g., hypoglycemia and ketosis, were seen. Serum and urine were collected before and $1 \mathrm{~h}, 2 \mathrm{~h}$, and $4 \mathrm{~h}$ after the loading test.

Challenge protein loading. With or without carnitine supplementation, the intake of natural protein by the patient was gradually increased, and the clinical course was observed.

$D, L$-Carnitine intravenous drip infusion. D,L-Carnitine $(50 \mathrm{mg} / \mathrm{kg})$ was intravenously infused within $30 \mathrm{~min}$, and serum and urine were collected before and after the infusion.

\section{RESULTS}

The serum levels of free carnitine before carnitine therapy were 10.81 and $6.49 \mathrm{nmol} / \mathrm{ml}$ (normal $53.22 \pm 6.82 \mathrm{nmol} / \mathrm{ml}$, mean $\pm 1 \mathrm{SD}$ ) (Table 1). After the supplementation, the level of free carnitine in the serum increased to a mean value of $25.33 \mathrm{nmol} / \mathrm{ml}$, still slightly low compared with normal levels. The acylcarnitines were already high in the serum before carnitine administration and increased to a maximal value of $58.57 \mathrm{nmol} / \mathrm{ml}$, after the carnitine administration. Before the administration, urinary excretion of free carnitine by the patient was lower than that by the controls, while acylcarnitine excretion in the patient was

Table 1. Serum and urine levels of carnitine before and after carnitine therapy.

\begin{tabular}{lccc}
\hline & Free & Acyl & Total \\
\hline Serum $(\mathrm{nmol} / \mathrm{ml})$ & & & \\
$\quad$ Before & $10.81,6.49$ & $34.67,35.66$ & $45.48,42.15$ \\
After & $22.02-29.04$ & $18.17-58.57$ & $47.21-86.86$ \\
Control & $53.22 \pm 6.82$ & $25.04 \pm 8.91$ & $78.25 \pm 7.56$ \\
\hline Urine (nmol/mg creatinine) & & & \\
Before & 12.42 & 568.82 & 581.26 \\
After & 557.87 & $1,882.36$ & $2,440.25$ \\
Control & $114.44 \pm 61.99$ & $219.37 \pm 100.35$ & $333.78 \pm 144.89$ \\
\hline
\end{tabular}

Control values are obtained for age matched healthy children without carnitine therapy. Mean $\pm \operatorname{SD}(n=10)$. 
about double that in the normal control. After the therapy, free carnitine excretion was increased to $557.87 \mathrm{nmol} / \mathrm{mg}$ creatinine, and acylcarnitine excretion also increased markedly to $1,882.36 \mathrm{nmol} / \mathrm{mg}$ creatinine.

The valine loading test resulted in a rapid decrease in the blood glucose level, but there was little change in the levels of ammonia, lactate, and pyruvate. Free fatty acids (FFA) and 3-hydroxybutyrate (3-OHB) in the serum, however, rose coincidentally with the fall in blood glucose (Table 2). Acidosis did not develop during the test, irrespective of supplementation with carnitine (data not shown). Changes in levels of serum and urine carnitine during the valine loading test are

Table 2. Metabolic changes in serum components during valine loading test.

\begin{tabular}{|c|c|c|c|c|c|c|c|c|}
\hline & \multicolumn{4}{|c|}{ Carnitine supplementation $(-)$} & \multicolumn{4}{|c|}{ Carnitine supplementation $(t)$} \\
\hline & Before & $1 \mathrm{~h}$ & $2 \mathrm{~h}$ & $4 \mathrm{~h}$ & Before & $1 \mathrm{~h}$ & $2 \mathrm{~h}$ & $4 \mathrm{~h}$ \\
\hline Glucose $(\mathrm{mg} / \mathrm{dl})$ & 83 & 74 & 63 & 34 & 87 & 76 & 68 & 35 \\
\hline 3-OHB (mM) & 0.13 & 0.41 & 0.82 & 1.39 & 0.19 & 0.69 & 1.76 & 4.01 \\
\hline FFA (mEq/liter) & 0.67 & 1.01 & 1.59 & 2.16 & 0.63 & 1.01 & 1.14 & 2.16 \\
\hline Lactate $(\mathrm{mg} / \mathrm{dl})$ & 25.0 & 21.8 & 23.5 & 17.4 & 25.4 & 12.9 & 12.6 & 15.2 \\
\hline Pyruvate (mg/dl) & 2.03 & 1.68 & 1.85 & 1.44 & 1.42 & 0.99 & 0.84 & 0.96 \\
\hline
\end{tabular}

Table 3. Changes in serum and urinary carnitine during valine loading test.

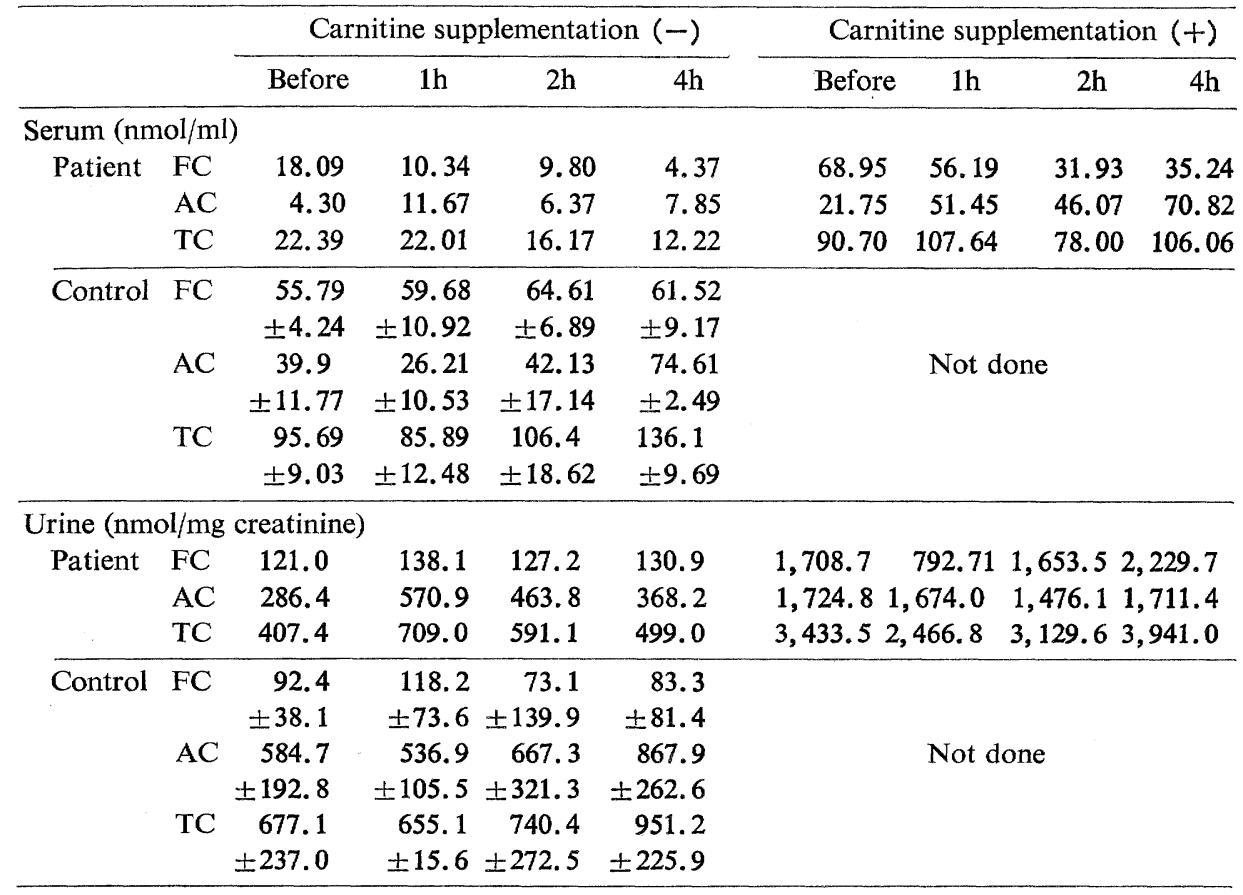

Control values are obtained for three adult volunteers. Mean \pm SD $(n=3)$. FC, Free carnitine; AC, acylcarnitine; TC, total carnitine. 
Table 4. Changes in serum and urinary glycine levels during valine loading test.

\begin{tabular}{|c|c|c|c|c|c|c|c|c|}
\hline & \multicolumn{4}{|c|}{ Carnitine supplementation $(-)$} & \multicolumn{4}{|c|}{ Carnitine supplementation $(t)$} \\
\hline & Before & $1 \mathrm{~h}$ & $2 \mathrm{~h}$ & $4 h$ & Before & $1 \mathrm{~h}$ & $2 \mathrm{~h}$ & $4 h$ \\
\hline Serum $(\mathrm{mg} / \mathrm{ml})$ & 8.3 & 4.9 & 4.4 & 2.4 & 7.7 & 6.9 & 6.4 & 5.1 \\
\hline $\begin{array}{l}\text { Urine } \\
\qquad(\mathrm{mg} / \mathrm{mg} \text { creatinine })\end{array}$ & 195.5 & 164.8 & 111.7 & 112.3 & 90.7 & 64.4 & 61.2 & 85.2 \\
\hline
\end{tabular}

Table 5. Metabolic changes in serum components before and after intravenous carnitine infusion.

\begin{tabular}{lcc}
\hline & Before & After \\
\hline Acetoacetate $(\mathrm{mM})$ & 0.34 & 0.20 \\
3-OHB $(\mathrm{mm})$ & 0.29 & 0.06 \\
FFA $(\mathrm{mEq} / \mathrm{liter})$ & 0.77 & 0.13 \\
Free carnitine $(\mathrm{nmol} / \mathrm{ml})$ & 19.4 & 106.2 \\
Lactate $(\mathrm{mg} / \mathrm{dl})$ & 37.4 & 32.9 \\
Pyruvate $(\mathrm{mg} / \mathrm{dl})$ & 2.1 & 1.5 \\
\hline
\end{tabular}

shown in Table 3. Without carnitine supplementation, the serum level of free carnitine was $18.09 \mathrm{nmol} / \mathrm{ml}$ and decreased gradually to $4.37 \mathrm{nmol} / \mathrm{ml} 4 \mathrm{~h}$ after valine loading, while there was little change in the controls. With carnitine therapy, the basal level of free carnitine in the serum increased to $68.95 \mathrm{nmol} / \mathrm{ml}$ and decreased after valine loading, but still remained within the normal range. Serum acylcarnitine, $4.30 \mathrm{nmol} / \mathrm{ml}$ without carnitine supplementation, increased to $11.67 \mathrm{nmol} / \mathrm{ml}$ after $1 \mathrm{~h}$ and decreased thereafter. With carnitine, plasma acylcarnitine increased gradually and showed the same pattern as the control without carnitine supplementation. Urinary excretion of free and acylcarnitine was also investigated. Without carnitine supplementation, the levels of free carnitine and acylcarnitine were within normal range, and showed little change during valine loading. On the contrary, after carnitine administration, the free carnitine and acylcarnitine in the urine were already markedly increased before the valine loading test, and they showed little change during the test. Before carnitine therapy the serum level of glycine was $8.3 \mathrm{mg} / \mathrm{dl}$ and then fell to $2.4 \mathrm{mg} / \mathrm{dl} 4 \mathrm{~h}$ after valine loading, representing a $71 \%$ decrease. However, under carnitine therapy, the serum level of glycine was $7.7 \mathrm{mg} / \mathrm{dl}$ before the test and dropped to $5.1 \mathrm{mg} / \mathrm{dl}$, showing only a $33.8 \%$ decrease after the loading (Table 4). Drip infusion of D,L-carnitine $(50 \mathrm{mg} / \mathrm{kg}$ ) was performed on the day following the first valine loading test. Serum carnitine increased from 19.4 to $106.2 \mathrm{nmol} / \mathrm{ml}$. Serum acetoacetate and 3-hydroxybutyrate were 0.34 and $0.29 \mathrm{~mm}$ and decreased to 0.20 and $0.06 \mathrm{~mm}$, respectively, after carnitine infusion. Free fatty acid also decreased from 0.77 to $0.13 \mathrm{mEq} /$ liter. Lactate and pyruvate showed little change (Table 5). Two natural protein loading tests were done. Without carnitine supplementation, the patient developed nausea and vomiting when receiving natural protein of $1.5 \mathrm{~g} / \mathrm{kg} /$ day, and her body weight decreased during the 4 days of the test. The patient did not manifest vomiting under carnitine supple- 
mentation, although nausea and appetite loss were observed. But these symptoms were so severe that the patient could not continue to receive natural protein of 1.5 $\mathrm{g} / \mathrm{kg} /$ day or more.

\section{DISCUSSION}

Our patient with methylmalonyl-CoA mutase deficiency had a low serum level of free carnitine but increased level of serum acylcarnitine. Acylcarnitine excretion was also elevated in contrast to the low level of free carnitine in the urine. The serum level of total carnitine was low, but within the normal ranges, suggesting that carnitine biosynthesis is probably not impaired in this patient [5]. A high ratio of acyl-/free carnitine in the plasma indicates the increased utilization of carnitine in vivo that results from the accumulation of acyl-CoA compounds in mitochondria, which are the substrates for carnitine acyltransferase [12]. It has been noted that the accumulation of acyl-CoA compounds, especially propionyl$\mathrm{CoA}$ and methylmalonyl-CoA, results in a secondary inhibition of pyruvate carboxylase [13], glycine cleavage enzyme [14], carbamylphosphate synthetase [15], and $\mathrm{N}$-acetylglutamate synthetase [16], which is thought to be a cause of hypoglycemia, hyperglycinemia and hyperammonemia in methylmalonic aciduria [17]. After the supplementation with carnitine, a marked increase in urinary excretion of free carnitine and acylcarnitine was noted, while only a small increase in the serum carnitine level was observed (Table 1). Some reports $[5,18,19]$ have revealed that urinary excretion of propionylcarnitine increases after carnitine therapy in patients with propionic acidemia and methylmalonic aciduria; but the possibility of increased excretion of other acylcarnitine groups, especially acetylcarnitine, has also been suggested [20]. After the valine loading test, we observed that levels of acylcarnitine in the serum and urine were increased in three normal volunteers (Table 3). A valine loading test of $50 \mathrm{mg} / \mathrm{kg}$ resulted in metabolic changes, e.g., hypoglycemia and hyperketonemia, with little change in serum levels of bicarbonate, lactate, pyruvate, and ammonia. The decrease in the serum glycine level after valine loading indicates the consumption of glycine by conjugation (Table 4). Propionylglycine and tiglylglycine were reported present in urine of patients of propionic acidemia and methylmalonic aciduria [21-23]. The level of glycine did not markedly decline with carnitine supplementation, as compared with the case of no carnitine therapy. This may indicate a glycine sparing effect of carnitine.

The changes in serum and urine levels of carnitine and its derivatives after valine loading indicate the utilization and importance of carnitine as a detoxication agent in this disorder. The decrease in free carnitine in the serum after the valine loading was observed even after the supplementation with carnitine (Table 3 ), which may be due to its smaller dose as compared with the large carnitine pool in the muscle. The dose of D,L-carnitine chloride was restricted because of its side effect, the myasthenic reaction [24]. Consequently, the early clinical use of L-carnitine seems necessary. D,L-Carnitine drip infusion $(50 \mathrm{mg} / \mathrm{kg})$ increased the serum 
level of free carnitine (to $106.2 \mathrm{nmol} / \mathrm{ml}$ ). The decrease in serum free fatty acid was suspected to be a result of stimulation of fatty acid oxidation by carnitine infusion $[4,25]$. A decrease in ketone bodies was also noticeable (Table 5). A high level of carnitine may stimulate the following reaction; acetyl-CoA + carnitine $\rightarrow$ acetylcarnitine. As acetylcarnitine was removed easily from intra- to extramitochondria, not only acetyl-CoA but also ketone bodies in the serum decreased. Yeh reported the antiketogenic action of carnitine [26]. Carnitine drip infusion seems useful in the management of acute episodes of methylmalonic aciduria. Although carnitine supplementation failed to increase a tolerance to natural protein in our patient, Roe et al. [18] reported successful carnitine treatment in a similar case. The reason for the difference between our results and theirs for carnitine therapy for methylmalonic aciduria is not clear, but a quantitative difference in deficiency of enzymes is suspected to be a main cause. In our case, the frequency of acute episodes decreased after carnitine supplementation and the patient showed a favorable body weight gain. Therefore, carnitine supplementation is considered as an effective supportive therapy in addition to dietary treatment.

\section{REFERENCES}

1. Akken, R.J., Hansch, D.B., and Wu, H.L.C. (1982): Hypocarnitinaemia in disorders of organic acid metabolism. Lancet II, 500-501.

2. Chalmers, R.A., Roe, C.R., Tracey, B.M., Stacey, T.E., Hoppel, C.L., and Millington, D.S. (1983): Secondary carnitine insufficiency in disorders of organic acid metabolism: modulation of acyl-CoA/CoA ratios by L-carnitine in vivo. Biochem. Soc. Trans., 11, 724-725.

3. Brass, E.P., and Hoppel, C.L. (1980): Relationship between acid-soluble carnitine and coenzyme A pools in vivo. Biochem. J., 190, 495-504.

4. Bieber, L.L., Emaus, R., Valkner, K., and Farrell, S. (1982): Possible functions of shortchain and medium-chain carnitine acyltransferases. Fed. Proc., 41, 2858-2862.

5. Roe, C.R., Millington, D.S., Maltby, D.A., Bohan, T.P., and Hoppel, C.L. (1984): L-Carnitine enhances excretion of propionyl coenzyme $\mathrm{A}$ as propionylcarnitine in propionic acidemia. J. Clin. Invest., 73, 1785-1788.

6. Seccombe, D.W., Snyder, F., and Parsons, H.G. (1982): L-Carnitine for methylmalonic aciduria. Lancet II, 1401.

7. Inoue, F., Kinugasa, K., and Hasegawa, T. (1983): A quantitative assay for methylmalonic acid by using chemical ionization selected ion monitoring. J. Kyoto Pref. Univ. Med., 92, 309-314.

8. McGarry, J.D., and Foster, D.W. (1976): An improved and simplified radioisotopic assay for the determination of free and esterified carnitine. J. Lipid Res., 17, 277-281.

9. Seccombe, D.W., Hahn, P., and Hovac, M. (1978): The effect of diet and development on blood levels of free and esterified carnitine in the rat. Biochim. Biophys. Acta, 528, 483-489.

10. Engel, A.G., Rebouche, C.J., Wilson, D.M., Glasgow, A.M., Romshe, C.A., and Cruse, R.P. (1981): Primary systemic carnitine deficiency. 11 Renal handling of carnitine. Neuro$\log y$, 31, 819-825.

11. Harano, Y., Kosugi, K., Hyosu, T., Uno, S., Ichikawa, Y., and Shigeta, Y. (1983): Sensitive and simplified method for the differential determination of serum levels of ketone bodies. Clin. Chim. Acta, 134, 327-336.

Vol. 2, No. 2, 1987 
12. Solberg, H.E. (1972): Different carnitine acyltransferase in calf liver. Biochim. Biophys. Acta, 280, 422-433.

13. Oberholzer, V.G., Levin, B., Burgess, E.A., and Young, W.F. (1967): Methylmalonic aciduria-an inborn error of metabolism leading to chronic metabolic acidosis. Arch. Dis. Childh., 42, 492-504.

14. Hayasaka, K., Narisawa, K., Satoh, T., Takeda, H., Metoki, K., Tada, K., Hiraga, K., Aoki, T., Kawakami, T., Akamatu, H., and Matsuo, N. (1982): Glycine cleavage system in ketotic hyperglycinemia: a reduction of $\mathrm{H}$-protein activity. Pediatr. Res., 16, 5-7.

15. Gruskey, J.A., and Rosenberg, L.E. (1979): Inhibition of hepatic mitochondrial carbamyl phosphate synthetase (CPSI) by acyl CoA esters. Possible mechanism of hyperammonemia in the organic acidemia. Pediatr. Res., 13, 475.

16. Coude, F.X., Sweetmann, L., and Nyhan, W.L. (1979): Inhibition by propionyl-coenzyme A of $\mathrm{N}$-acetylglutamate synthetase in rat liver mitochondria. A possible explanation for hyperammonemia in propionic and methylmalonic acidemia. J. Clin. Invest., 64, 1544-1551.

17. Rosenberg, L.E. (1983): Disorders of propionate and methylmalonate metabolism, in The Metabolic Basis of Inherited Disease (5th ed), ed. by Stanbury, J.B., Wyngaarden, J.B., Fredrickson, D.S., Goldstein, J.L., and Brown, M.S., McGraw-Hill, New York, pp. 474-497.

18. Roe, C.R., Hoppel, C.L., Stacey, T.E., Chalmers, R.A., Tracewy, B.M., and Millington, D.S. (1983): Metabolic response to carnitine in methylmalonic aciduria-an effective strategy for elimination of propionyl groups. Arch. Dis. Childh., 58, 916-920.

19. Donato, S.D., Rimmoldi, M., Garavaglia, B., and Uziel, G. (1984): Propionyl carnitine excretion in propionic and methylmalonic aciduria: a cause of carnitine deficiency. Clin. Chim. Acta, 139, 13-21.

20. Roe, C. (1984): Relative carnitine insufficiency in Reyes syndrome and other metabolic disorders. The 4th international Conference on Reyes Syndrome, Columbus, Ohio.

21. Bartlett, K., and Gompertz, D. (1974): The specificity of glycine-N-acylase and acylglycine excretion in the organic acidemias. Biochem. Med., 10, 15-23.

22. Rasmussen, K., Ando, T., Nyhan, W.L., Hull, D., Cottom, D., Donnell, G., Wadlington, W., and Kilroy, A.W. (1972): Excretion of propionylglycine in propionic acidaemia. Clin. Sci., 42, 665-671.

23. Roe, C.R., and Bohan, T.P. (1982): L-Carnitine therapy in propionic acidaemia. Lancet I, 1411-1412.

24. de Grandis, D., Mezzina, C., Fiaschi, A., Pinelli, P., Bazzato, G., and Morachiello, M. (1980): Myasthemia due to carnitine treatment. J. Neurol. Sci., 46, 365-371.

25. Seccombe, D.W., and Hahn, P. (1980): Carnitine acetyltransferase in developing mammals. Biol. Neonate., 38, 90-95.

26. Yeh, Y. (1981): Antiketonemic and antiketogenic action of carnitine in vivo and in vitro in rats. J. Nutr., 111, 831-840. 